\title{
Níveis séricos de IgG anti-Trypanosoma cruzi na evolução da cardiopatia chagásica crônica, no período de 10 anos
}

\author{
Sera levels of Ig G anti-Trypanosoma cruzi on evolution of the \\ chronic chagasic cardiopathy in interval of 10 years \\ Patrícia Lago Zauza1 e José Borges-Pereira ${ }^{1}$
}

\begin{abstract}
Resumo Com o objetivo de investigar a relação entre os níveis de anticorpos (lgG) anti-T. cruzi e a evolução da cardiopatia chagásica crônica, no período de 10 anos, foi realizado um estudo envolvendo soros de 140 pacientes não submetidos ao tratamento específico de Virgem da Lapa, Minas Gerais. Entre os pacientes, 92 são mulheres e 48 homens, com idades ao exame inicial de 10 a 70 anos (média $=38 \pm 13,7$ anos). Os níveis de anticorpos foram estimados pelas médias dos títulos registrados através dos testes de imunofluorescência indireta e hemaglutinação indireta, e pelo índice de reatividade (D.O. da amostra /cut-off) indicado nos testes ELISA convencional e recombinante CRA+FRA. No período, 49 pacientes se mantiveram sem cardiopatia, 29 desenvolveram cardiopatia, 33 mantiveram o grau inicial da cardiopatia, 25 evoluíram com agravamento da cardiopatia inicial e 4 normalizaram o eletrocardiograma. A análise dos resultados de todos os testes sorológicos mostrou aumento estatisticamente significativo dos níveis de IgG anti-T. cruzi no grupo de pacientes com evolução progressiva da cardiopatia principalmente na faixa etária de 20 a 59 anos, independentemente do sexo. Estes resultados indicaram uma associação direta entre os níveis séricos desses anticorpos e a evolução progressiva da cardiopatia chagásica crônica.
\end{abstract}

Palavras-chaves: Doença de Chagas. Cardiopatia chagásica crônica. Sorologia. Imunoglobulinas G. Estudo longitudinal.

\begin{abstract}
In order to investigate the relationship between T. cruzi specific antibodies (IgG) levels and the clinical course of chronic chagasic cardiopathy, the authors analyzed sera from 140 non-treated patients with specific drugs from Virgem da Lapa, Minas Gerais, during 10 years. Of these patients, 92 were women and 48 men, varying from 10 to 70 years old (mean $=38 \pm 13.5$ years). Antibody levels were estimated by the mean of titers obtained by an indirect immunofluorescence test, indirect hemagglutination assay and by the mean reactivity indexes (OD/cut-off) obtained by ELISA tests using a conventional antigens and recombinant proteins (CRA+FRA). During the study period, the course of the disease was as follows: 49 did not present cardiac alterations, 29 coursed to cardiopathy, 33 maintained initial cardiopathy, 25 evolved with aggravation of the cardiopathy and 4 with normalization of the electrocardiogram. Statistical analysis showed a significant increase in antibody levels among patients in the group with progressive cardiopathy, as well as in patients with age interval of 20 to 59 years, independent of sex. These findings indicated a direct association between T. cruzi specific antibodies (IgG) levels and the clinical course of chronic chagasic cardiopathy.
\end{abstract}

Key-words: Chagas' disease. Chronic chagasic cardiopathy. Serology. Immunoglobulins G. Longitudinal study.

Apesar dos estudos longitudinais sobre a doença de Chagas demonstrarem o caráter progressivo das formas clínicas 36813 , persistem as indagações em torno do papel de fatores ligados ao parasita, ao hospedeiro ou a ambos no processo evolutivo. Em relação ao hospedeiro, poucos estudos têm sido realizados principalmente em busca de marcadores genéticos, entretanto no campo dos fatores ligados à resposta imune tem sido demonstrada a participação da imunidade celular na patogenia da cardiopatia ${ }^{20}$, enquanto são controversos os resultados sobre a participação da resposta imune representada pelas imunoglobulinas 12182124.

Há estudos que referem diferenças nos perfis qualitativos e quantitativos das imunoglobulinas séricas nas diferentes fases e formas clínicas da doença de Chagas ${ }^{10111619}$, em diferentes populações ${ }^{417}$ e em

\footnotetext{
1. Departamento de Medicina Tropical do Instituto Oswaldo Cruz da Fundação Osvaldo Cruz, Rio de Janeiro, RJ, Brasil. Apoio financeiro: $\mathrm{CNPq}$

Endereço para correspondência: Dra. Patrícia Lago Zauza. Av. Brasil 4365, Pavilhão Arthur Neiva, Manguinhos, $21045-900$ Rio de Janeiro, RJ, Brasil. e-mail: borges@ioc.fiocruz.br

Recebido para publicação em 9/5/2001.
} 
função do tratamento específico ${ }^{1914}$. Entretanto, verificase a carência de estudos longitudinais por longo intervalo de tempo, com o monitoramento simultâneo dos níveis séricos de anticorpos anti-T. cruzi e das formas clínicas na ausência de tratamento específico. A partir dessa constatação, decidimos realizar o presente trabalho com o objetivo principal de avaliar os níveis de anticorpos anti-T. cruzi em função da evolução da cardiopatia chagásica crônica em pacientes não submetidos ao tratamento específico no intervalo de 10 anos.

\section{MATERIAL E MÉTODOS}

Casuística. De um grupo de 835 pacientes chagásicos crônicos de Virgem da Lapa, Minas Gerais, constituído a partir de 1984, foram selecionados 140 pacientes que apresentavam evolução clínica e eletrocardiográfica, no intervalo médio de 10 anos (1984-1994), sem tratamento específico principalmente por recusas, contraindicações e migrações periódicas para trabalhar em outras áreas impossibilitando o controle necessário no uso de benznidazol. Desses pacientes, 92 eram do sexo feminino e 48 do sexo masculino com idades de 10 a 70 anos (média $=38 \pm 13,7$ anos) na época do primeiro exame. No estudo clínico evolutivo realizado nesse período, entre os 78 pacientes sem cardiopatia ao exame inicial, 49 permaneceram inalterados (G1) e 29 desenvolveram cardiopatia (G2), enquanto entre os 62 com cardiopatia ao exame inicial, 33 permaneceram inalterados (G3), 25 apresentaram agravamento da cardiopatia (G4) e 4 apresentaram normalização do eletrocardiograma $\left(G_{5}\right)^{2}$. O comprometimento do aparelho digestivo não foi considerado em decorrência da não realização do exame radiológico na avaliação final.

Testes sorológicos e critérios de evolução. Foram consideradas as duas amostras de soros obtidas no intervalo de 10 anos, armazenadas a $-20^{\circ} \mathrm{C}$ na soroteca do Departamento de Medicina Tropical do Instituto Oswaldo Cruz. A pesquisa de Ig/G sérica anti-T. cruzi foi realizada em outubro de 1999 de maneira pareada através dos testes de imunofluorescência indireta (IFI), hemaglutinação indireta (HAI), ELISA convencional (ELISA-c) e ELISA com recombinantes CRA e FRA (ELISA-r), obedecendo às recomendações dos fabricantes quanto à utilização dos reagentes, leitura e interpretação dos resultados. Na IFI empregando como antígenos formas epimastigotas do T. cruzi obtidas de cultivo (Kit IFI-Chagas-Bio-Manguinhos, lote 9904Cl01Z-0400, validade abril de 2000) e HAI empregando hemácias de aves sensibilizadas com antígenos solúveis totais de T. cruzi (Kit HemacruziBiolab, lote H90651G, validade junho de 2000) os soros foram testados em diluições na razão 2 , a partir de 1:40, enquanto na ELISA-c empregando como antígenos à fração solúvel purificada de T. cruzi (Kit EIE-doença de Chagas, Bio-manguinhos, lote 9906ST01Z, validade dezembro de 1999) foram testados em diluição única de 1:100 e na ELISA-r empregando os antígenos recombinantes CRA e FRA (Kit ElE-recombinante-doença de Chagas, BioManguinhos, validade janeiro de 2000) foram testados $50 \mu$ in natura.

Consideramos como indicadores de evolução do nível de anticorpos IgG anti-T. cruzi a variação dos títulos revelada pelos testes de IFI e HAI e dos índices de reatividade (D.O da amostra/cut-off) reveladas pelas ELISAs. Para cada teste classificamos a evolução sorológica nos seguintes tipos: inalterada $=$ variação dos títulos $<2$ diluições e dos índices de reatividade $(\mathrm{IR})<1,5$ vezes, progressiva = aumento dos títulos ${ }^{3}$ 2 diluições e do IR ${ }^{31,5}$ vezes e regressiva = queda dos títulos 2 diluições e do IR 1,5 vezes.

Análise estatística. Os dados foram analisados com o auxílio do programa Epi-info versão 6.0 (Pan American Health Organization/World Health Organization). O teste de Kruskal-Wallis e o teste de análise de variância foram usados para comparar as médias geométricas dos títulos de anticorpos anti-T. cruzi e de sua tendência no estudo evolutivo. O qui-quadrado e o teste exato de Fisher foram usados para comparar diferenças entre as freqüências. O nível de significância considerado foi de $95 \%$ em todas as análises realizadas.

Aspectos éticos. Todas as amostras de soros avaliadas neste estudo foram obtidas por consentimento pós-informação das pessoas nas ocasiões dos estudos realizados por Dr. Borges-Pereira e outros pesquisadores a partir de 1984, no município de Virgem da Lapa.

\section{RESULTADOS}

Considerando os resultados qualitativos dos testes nas duas amostras de soros, 16 pacientes apresentaram discrepâncias, sendo 14 em um dos testes e dois pela HAI e ELISA convencional (Tabela 1). A HAI mostrou negatividade nas amostras de soros de sete pacientes, negativação em dois e positivação em um. A ELISA convencional mostrou negativação em dois pacientes e positivação em outros dois e a ELISA recombinante mostrou negativação em dois pacientes e positivação também em outros dois pacientes.
Considerando o tipo de evolução sorológica de cada teste empregado (Tabela 2), o percentual de pacientes com evolução sorológica inalterada foi significativamente maior do que o percentual de pacientes com evolução sorológica progressiva a partir dos resultados da IFI, HAI e ELISA-c, enquanto pela ELISA-r a diferença entre os percentuais não foi significativa. A evolução sorológica regressiva, identificada em maior percentual de pacientes pela ELISA-r, não foi revelada pelo teste de IFI. 
Considerando os 140 pacientes estudados, a análise comparativa das médias inicial e final de anticorpos IgG anti-T. cruzi nos soros mostrou a média final significativamente maior do que a média inicial em todos os testes empregados (Figura 1).
Em função da faixa etária, a média final foi significativamente maior do que a média inicial entre os pacientes com idades de 20 a 59 anos, sendo mais acentuada na faixa de 40 a 59 anos, tanto pelos testes de IFI e HAI (Tabela 3) como pelos testes de

Tabela 1- Características dos pacientes com discrepâncias nos resultados dos testes sorológicos.

\begin{tabular}{|c|c|c|c|c|c|c|c|c|c|c|c|}
\hline \multirow{2}{*}{ Paciente } & \multirow{2}{*}{ Id } & \multirow{2}{*}{ Sx } & \multirow{2}{*}{ EVC } & \multicolumn{2}{|c|}{$\mathrm{IFI}\left({ }^{*}\right)$} & \multicolumn{2}{|c|}{$\operatorname{HAI}\left({ }^{*}\right)$} & \multicolumn{2}{|c|}{ ELISA-c $\left({ }^{* *}\right)$} & \multicolumn{2}{|c|}{ ELISA-r $\left({ }^{* *}\right)$} \\
\hline & & & & inicial & final & inicial & final & inicial & final & inicial & final \\
\hline 143 & 31 & M & G4 & 320 & 320 & $\mathbf{N}$ & $\mathbf{N}$ & 1,8 & 2,1 & 27,0 & 30,5 \\
\hline 182 & 35 & M & G4 & 320 & 320 & 40 & 80 & 5,5 & 7,5 & 0,9 & 4,3 \\
\hline 249 & 32 & $\mathrm{~F}$ & G1 & 160 & 640 & $\mathbf{N}$ & 80 & 2,9 & 4,4 & 7,7 & 17,3 \\
\hline 350 & 45 & $\mathrm{~F}$ & G3 & 80 & 80 & $\mathbf{N}$ & $\mathbf{N}$ & 3,6 & 0,7 & 9,2 & 1,2 \\
\hline 378 & 34 & $\mathrm{~F}$ & G2 & 80 & 80 & $\mathbf{N}$ & $\mathbf{N}$ & 2,3 & 3,7 & 2,0 & 1,5 \\
\hline 758 & 48 & M & G4 & 160 & 160 & 80 & 640 & 3,2 & 9,7 & 0,7 & 11,0 \\
\hline 892 & 60 & $\mathrm{~F}$ & G2 & 80 & 320 & 80 & $\mathbf{N}$ & 2,2 & 0,7 & 8,1 & 4,0 \\
\hline 1108 & 38 & $\mathrm{~F}$ & G3 & 160 & 640 & $\mathbf{N}$ & $\mathbf{N}$ & 4,1 & 7,9 & 20,5 & 36,0 \\
\hline 1121 & 50 & $\mathrm{~F}$ & G2 & 160 & 320 & $\mathbf{N}$ & $\mathbf{N}$ & 2,7 & 2,7 & 12,8 & 12,2 \\
\hline 1284 & 48 & $M$ & G3 & 320 & 320 & $\mathbf{N}$ & $\mathbf{N}$ & 2,8 & 2,7 & 11,8 & 2,9 \\
\hline 1287 & 19 & $M$ & G1 & 80 & 320 & 80 & 320 & 0,8 & 5,4 & 9,6 & 23,0 \\
\hline 1381 & 36 & $\mathrm{~F}$ & G1 & 80 & 320 & 320 & 160 & 2,9 & 3,8 & 5,4 & 0,8 \\
\hline 1493 & 32 & $\mathrm{~F}$ & G3 & 320 & 320 & 40 & $\mathbf{N}$ & 2,8 & 2,8 & 29,5 & 13,2 \\
\hline 1498 & 38 & $\mathrm{~F}$ & G3 & 640 & 1280 & 1280 & 640 & 12,7 & 8,8 & 7,1 & 0,7 \\
\hline 1513 & 58 & $\mathrm{~F}$ & G1 & 160 & 640 & $\mathbf{N}$ & $\mathbf{N}$ & 6,6 & 9,8 & 16,5 & 9,5 \\
\hline 1840 & 60 & $\mathrm{~F}$ & G3 & 320 & 1280 & 160 & 1280 & 0,7 & 1,2 & 23,7 & 15,1 \\
\hline
\end{tabular}

$\left({ }^{*}\right)=$ inverso do título; $\left({ }^{* *}\right)=$ índice de reatividade, Id = idade na época do primeiro exame; EVC = evolução clínica; ELISA-c = ELISA convencional; ELISA-r = ELISA recombinante CRA+FRA; G1 = paciente sem cardiopatia, G2 = paciente que evoluiu para cardiopatia, G3 = paciente com cardiopatia inicial inalterada, G4 = paciente com agravamento da cardiopatia inicial, $\mathrm{N}=$ negativa

Tabela 2 -Tipos de evolução sorológica de acordo com o teste aplicado em soros obtidos no intervalo de 10 anos de 140 pacientes chagásicos crônicos.

\begin{tabular}{llrrr}
\hline \multirow{2}{*}{ Testes sorológicos } & \multicolumn{2}{c}{ Tipos de evolução sorológica* } & \multirow{2}{*}{$\begin{array}{c}\text { Total de } \\
\text { pacientes }\end{array}$} \\
\cline { 2 - 4 } & Inalterada & Progressiva & Regressiva & \\
\hline IFI & $88(63,9 \%)$ & $52(37,1 \%)$ & $0(\ldots)$ & 140 \\
HAI & $84(60,0 \%)$ & $49(35,0 \%)$ & $7(5,0 \%)$ & 140 \\
ELISA convencional & $81(57,9 \%)$ & $52(37,1 \%)$ & $7(5,0 \%)$ & 140 \\
ELISA recombinante CRA+FRA & $60(42,9 \%)$ & $63(45,0 \%)$ & $17(12,1 \%)$ & 140 \\
\hline
\end{tabular}

* critérios em material e métodos
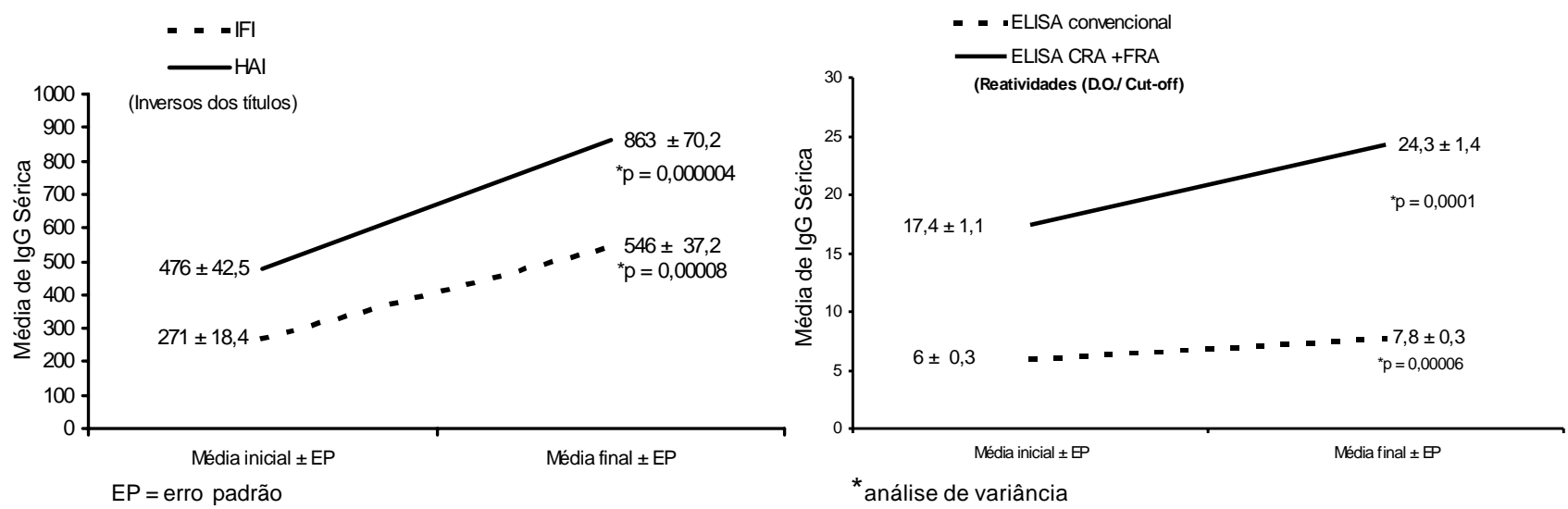

Figura 1 - Evolução das médias de lgG anti-T. cruzi em soros de 140 chagásicos crônicos, no período de 10 anos. 
ELISA-c e ELISA-r (Tabela 4). Essa diferença significativa também foi observada em ambos os sexos, com maior intensidade entre as mulheres.

Em relação à evolução da cardiopatia (Tabelas $3 \mathrm{e}$ 4), os testes empregados registraram a média final significativamente maior do que a média inicial no grupo de pacientes sem cardiopatia (G1), no grupo de casos novos de cardiopatia (G2) e no grupo de pacientes com agravamento da cardiopatia inicial (G4). Por outro lado, no grupo de pacientes com cardiopatia inicial inalterada (G3) e no grupo com normalização do ECG a diferença entre as médias inicial e final não foi estatisticamente significativa.

Tabela 3 - Evolução das médias dos títulos de IgG anti-T. cruzi, pela IFI e HAl, em soros obtidos de 140 pacientes chagásicos crônicos, no intervalo de 10 anos.

\begin{tabular}{|c|c|c|c|c|c|c|c|}
\hline \multirow{2}{*}{ Variáveis } & \multirow{2}{*}{ Pacientes } & \multicolumn{3}{|c|}{ Imunofluorescência indireta } & \multicolumn{3}{|c|}{ Hemaglutinação indireta } \\
\hline & & $\begin{array}{l}\text { média inicial } \\
\pm \pm E P\end{array}$ & $\begin{array}{c}\text { média final } \\
\pm E P\end{array}$ & $\left({ }^{*}\right) p=$ & $\begin{array}{l}\text { média inicial } \\
\pm \pm E P\end{array}$ & $\begin{array}{c}\text { média final } \\
\pm E P\end{array}$ & $\left({ }^{*}\right) p=$ \\
\hline \multicolumn{8}{|l|}{ Faixa etária (anos)* } \\
\hline $10-19$ & 9 & $186 \pm 15,8$ & $462 \pm 29,8$ & 0,050 & $235 \pm 33,3$ & $684 \pm 48,3$ & 0,066 \\
\hline $20-39$ & 53 & $246 \pm 14,9$ & $466 \pm 35,8$ & 0,0006 & $478 \pm 45,8$ & $838 \pm 65,1$ & 0,006 \\
\hline $40-59$ & 68 & $281 \pm 17,9$ & $609 \pm 38,6$ & 0,000000 & $524 \pm 42,0$ & $923 \pm 79,4$ & 0,002 \\
\hline$\geq 60$ & 10 & $408 \pm 33,0$ & $624 \pm 39,5$ & 0,274 & $352 \pm 31,6$ & $752 \pm 42,3$ & 0,055 \\
\hline \multicolumn{8}{|l|}{ Sexo } \\
\hline Feminino & 92 & $278 \pm 18,5$ & $543 \pm 38,7$ & 0,000001 & $476 \pm 44,1$ & $921 \pm 70,6$ & 0,00002 \\
\hline Masculino & 48 & $257 \pm 18,3$ & $553 \pm 34,7$ & 0,00002 & $475 \pm 39,8$ & $753 \pm 68,8$ & 0,042 \\
\hline \multicolumn{8}{|l|}{ Grupos de pacientes- evolução } \\
\hline G1- sem cardiopatia & 49 & $240 \pm 19,0$ & $538 \pm 45,4$ & 0,0005 & $388 \pm 38,8$ & $756 \pm 53,8$ & 0,001 \\
\hline G2 - desenvolveram cardiopatia & 29 & $297 \pm 22,8$ & $631 \pm 35,0$ & 0,049 & $488 \pm 46,6$ & $973 \pm 60,0$ & 0,005 \\
\hline G3 - cardiopatia inalterada & 33 & $294 \pm 16,1$ & $395 \pm 20,5$ & 0,065 & $529 \pm 46,8$ & $844 \pm 84,5$ & 0,117 \\
\hline G4 - agravamento da cardiopatia inicial & al 25 & $241 \pm 12,8$ & $649 \pm 37,0$ & 0,044 & $566 \pm 39,1$ & $1036 \pm 89,2$ & 0,0003 \\
\hline G5 - normalização do ECG & 4 & $440 \pm 20,3$ & $640 \pm 38,3$ & 0,452 & $460 \pm 47,0$ & $450 \pm 47,8$ & 0,980 \\
\hline
\end{tabular}

*ao exame inicial, $\left({ }^{*}\right)$ teste de Kruskal-Wallis e análise de variância

Tabela 4 - Evolução das médias dos índices de reatividade de IgG anti-T. cruzi, pela ELISA convencional e recombinante (CRA+FRA), em soros de 140 pacientes chagásicos crônicos, no intervalo de 10 anos.

\begin{tabular}{|c|c|c|c|c|c|c|c|}
\hline \multirow{2}{*}{ Variáveis } & \multirow{2}{*}{ Pacientes } & \multicolumn{3}{|c|}{ ELISA convencional } & \multicolumn{3}{|c|}{ ELISA recomendado CRA+CFA } \\
\hline & & $\begin{array}{l}\text { média inicial } \\
\pm \pm E P\end{array}$ & $\begin{array}{c}\text { média final } \\
\pm E P\end{array}$ & $\overline{\left({ }^{*}\right) p=}$ & $\begin{array}{l}\text { média inicial } \\
\pm \pm E P\end{array}$ & $\begin{array}{c}\text { média final } \\
\pm E P\end{array}$ & $\overline{\left({ }^{*}\right) p=}$ \\
\hline \multicolumn{8}{|l|}{ Faixa etária (anos) ${ }^{\star}$} \\
\hline $10-19$ & 9 & $5,6 \pm 0,30$ & $7,7 \pm 0,23$ & 0,081 & $15,4 \pm 0,96$ & $22,1 \pm 1,05$ & 0,258 \\
\hline $20-39$ & 53 & $5,9 \pm 0,30$ & $7,5 \pm 0,34$ & 0,038 & $16,2 \pm 1,03$ & $24,0 \pm 1,42$ & 0,007 \\
\hline $40-59$ & 68 & $6,1 \pm 0,26$ & $8,2 \pm 0,32$ & 0,0005 & $18,1 \pm 1,18$ & $25,4 \pm 1,46$ & 0,007 \\
\hline$\geq 60$ & 10 & $6,7 \pm 0,33$ & $6,8 \pm 0,33$ & 0,947 & $20,7 \pm 1,38$ & $20,3 \pm 1,23$ & 0,952 \\
\hline \multicolumn{8}{|l|}{ Sexo } \\
\hline Mulheres & 92 & $5,5 \pm 0,27$ & $7,2 \pm 0,30$ & 0,001 & $16,6 \pm 1,14$ & $23,7 \pm 1,33$ & 0,001 \\
\hline Homens & 48 & $7,0 \pm 0,29$ & $9,0 \pm 0,33$ & 0,012 & $18,8 \pm 1,11$ & $25,5 \pm 1,54$ & 0,041 \\
\hline \multicolumn{8}{|l|}{ Grupos de pacientes- evolução } \\
\hline G1- sem cardiopatia & 49 & $5,3 \pm 0,28$ & $7,4 \pm 0,27$ & 0,002 & $15,2 \pm 0,96$ & $23,3 \pm 1,05$ & 0,001 \\
\hline G2 - desenvolveram cardiopatia & 29 & $5,6 \pm 0,26$ & $8,0 \pm 0,34$ & 0,017 & $16,5 \pm 1,05$ & $24,5 \pm 1,43$ & 0,044 \\
\hline G3 - cardiopatia inicial inalterada & 33 & $7,1 \pm 0,30$ & $7,4 \pm 0,28$ & 0,786 & $19,8 \pm 1,29$ & $24,7 \pm 1,71$ & 0,277 \\
\hline G4 - agravamento da cardiopatia inicial & 25 & $6,5 \pm 0,27$ & $9,4 \pm 0,38$ & 0,012 & $18,7 \pm 1,32$ & $27,0 \pm 1,64$ & 0,010 \\
\hline G5 - normalização do ECG & 4 & $5,7 \pm 0,29$ & $4,8 \pm 042$ & 0,772 & $21,4 \pm 0,76$ & $15,3 \pm 0,58$ & 0,305 \\
\hline
\end{tabular}

*ao exame inicial, $\left({ }^{*}\right)$ teste de Kruskal-Wallis e análise de variância 


\section{DISCUSSÃO}

Ao realizarmos este trabalho com soros armazenados a $-20^{\circ} \mathrm{C}$ por mais de uma década, sem antecedente na literatura, consideramos a possibilidade de que essas condições pudessem influir de maneira significativa nos resultados, o que determinaria maior freqüência de evolução sorológica progressiva. Contudo, observamos maior freqüência de evolução sorológica inalterada, além do registro de evolução regressiva, indicando que as condições de armazenamento citadas não influíram de modo significativo nos resultados. Willcox et $\mathrm{al}^{25}$ e Castro et $\mathrm{al}^{5}$ utilizando os testes de IFI e ELISA convencional não encontraram variações significativas nos níveis de anticorpos em soros armazenados por até dois anos $\mathrm{a}-20^{\circ} \mathrm{C}$.

A aplicação dos testes sorológicos como instrumentos de medidas dos níveis de anticorpos lg G anti- $T$. cruzi em soros está fundamentada no bom desempenho que os mesmos têm apresentado em estudos seccionais qualitativos e quantitativos 222326 , além da comprovada indicação para avaliar a eficácia do tratamento específico na doença de Chagas ${ }^{19} 14$.

No pequeno número de estudos, correlacionando os níveis séricos de anticorpos anti- $T$. cruzi com as formas clínicas da doença de Chagas crônica não submetida ao tratamento específico destaca-se a investigação de natureza seccional realizada por Gusmão et $\mathrm{al}^{10}$ com soros de 217 chagásicos crônicos de Goiás, observando maiores médias desses anticorpos pela aglutinação direta no grupo de pacientes na forma clínica digestiva e cardíaca grave. Também em estudo seccional Zauza ${ }^{26}$ avaliando soros de 835 chagásicos crônicos de Virgem da Lapa, Minas Gerais, encontrou maiores níveis pelos testes de IFI e HAl no grupo de pacientes na forma cardíaca.

Cotejando a literatura sobre estudos sorológicos longitudinais envolvendo pacientes chagásicos crônicos não submetidos ao tratamento específico verificamos o trabalho realizado por Luquetti et al $^{15}$ com soros de 10 chagásicos de Goiás, avaliados pelos testes de IFI, HAI e ELISA convencional, no intervalo máximo de 21 meses, encontrando variações não significativas dos títulos. Enquanto no presente estudo observamos aumento significativo dos níveis de anticorpos em percentuais de pacientes que variaram de $37 \%$ pela IFI a $45 \%$ pela ELISAr. Provavelmente a discordância entre esses resultados possa ser atribuída aos diferentes intervalos de tempo, número e origem dos pacientes, além das questões técnicas dependentes de variações nos componentes dos kits empregados assim como as diferenças laboratoriais.

No presente trabalho verificamos oscilações nos níveis de anticorpos com negativação ou positivação de soros pelas ELISAs e HAI. Estas oscilações podem ser consideradas esperadas, diante do amplo espectro de resultados encontrados em estudos sorológicos na doença de Chagas crônica, as quais podem ser conseqüências das características dos testes empregados ou da dinâmica da interação T. cruzihomem, com repercussões tanto na resposta imune como na evolução da doença.

Merece destaque o achado de negatividade persistente nas duas amostras de soros somente pela $\mathrm{HAl}$ em sete pacientes com diferentes características clínicas evolutivas, de ambos os sexos e diferentes idades. Não encontramos explicação consistente para este achado. Embora, admitamos a possibilidade de existirem fatores impeditivos da reação antígenoanticorpo, nos soros destes pacientes, dirigidos para o teste de HAl utilizado neste estudo. Cabe também salientar que não houve negativação sorológica pelos quatro testes empregados, sinalizando para a ausência de cura espontânea no período. Contudo, houve queda dos níveis de anticorpos, identificada pelos testes de HAI e ELISAs, nos quatro pacientes que evoluíram com normalização do ECG, o que pode ser indicativo de que a negativação sorológica em pacientes sem tratamento específico acompanha a regressão da doença, porém necessita de tempo maior para sua definição.

O aumento significativo dos níveis de anticorpos revelado por todos os testes entre os pacientes na faixa etária de 20 a 59 anos e não significativo entre os pacientes maiores de 60 anos de ambos os sexos nos conduziu a uma análise comparativa com o perfil evolutivo da doença, resultando numa correlação positiva entre a progressão da doença e aumento dos níveis de anticorpos em função da faixa etária. Neste contexto, destacamos também que todos os testes identificaram aumento significativo dos níveis de anticorpos no grupo de pacientes sem cardiopatia ao exame inicial, tanto entre os que assim permaneceram (G1) como entre os apresentaram doença cardíaca ao exame final (G2), indicando o elevado potencial de oscilação dos níveis de lg G anti-T. cruzi entre os pacientes com maior potencial de evolução progressiva da doença ${ }^{678}$.

No campo das especulações, estas observações adquirem importância por diversos aspectos. Em primeiro lugar, porque pode ser a expressão indireta de uma possível instabilidade na interação entre o parasito e o homem (hospedeiro em questão) e em segundo lugar, porque, nestes pacientes, a queda dos níveis de anticorpos, com tratamento específico ou não, pode ser indicativo de estabilização ou redução da intensidade desta interação ou até mesmo de cura. Esta última hipótese pode ser justificada pelos resultados deste trabalho que mostraram aumento significativo dos níveis de anticorpos entre os pacientes com agravamento da cardiopatia inicial (G4), 
não significativo entre os pacientes com evolução inalterada da cardiopatia inicial (G3) e redução dos níveis entre os pacientes que normalizaram 0 eletrocardiograma (G5), indicativo de possível redução da morbidade cardíaca.

A importância do conhecimento sobre o comportamento dos níveis de anticorpos na doença de Chagas tem sido evidenciada principalmente em estudos que avaliam à eficácia do tratamento específico. Nessa direção, Andrade et al $^{1}$ relatam a queda dos níveis de anticorpos anti-T. cruzi, pelos testes de IFI, HAl e ELISA convencional no grupo de chagásicos com idades de 7 a 12 anos, três anos depois de terem sido tratados com benznidazol em comparação com o grupo controle que usou placebo. Também Estani et $\mathrm{al}^{9}$, em estudo longitudinal de quatro anos, empregando os mesmos testes sorológicos, observaram a queda significativa dos níveis de anticorpos séricos anti-T. cruzi no grupo de crianças na forma clínica indeterminada submetida ao tratamento com a mesma droga em comparação com o grupo controle que usou placebo.
O envolvimento da imunidade celular no processo determinante de lesões miocárdicas no curso da infecção pelo T. cruzi ${ }^{20}$ tem sido demonstrado enquanto o envolvimento da imunidade humoral representada pelas imunoglobulinas ainda está por ser claramente definido, considerando que o conhecimento existente sobre a integração e cooperação dos componentes celular e molecular do sistema imune durante o processo infeccioso fundamenta essa investigação.

Apesar dos resultados do presente trabalho indicarem uma associação direta entre os níveis circulantes de Ig G anti- $T$. cruzi e a progressão da cardiopatia chagásica crônica, os limites da casuística e métodos empregados não nos permitem concluir sobre a participação dessas imunoglobulinas na patogenia da lesão miocárdica, mas, apenas, nos permitem afirmar que a intensidade da resposta imune humoral, representada por essas imunoglobulinas, está diretamente associada à evolução clínica da cardiopatia chagásica crônica.

\section{AGRADECIMENTOS}

Os autores agradecem a Antonio Gomes Pinto Ferreira e Edmilson Domingos da Silva do Laboratório de Tecnologia Diagnóstica, Bio-Manguinhos, Fiocruz, pelo fornecimento dos kits para os testes sorológicos de imunofluorescência indireta, ELISA convencional e ELISA recombinante empregados neste trabalho; ao técnico José de Souza Nogueira, Departamento de Medicina Tropical pela colaboração na realização das técnicas e ao Dr. Nelson Chagas pelas sugestões na aplicação dos métodos estatísticos.

\section{REFERÊNCIAS BIBLIOGRÁFICAS}

1. Andrade ALSS, Zicker F, Oliveira RM, Almeida SS, Luquetti A, Travassos LR, Almeida IC, Andrade SS, Andrade JG, Martelli CMT. Randomised trial of efficacy of benznidazole in treatment of early Trypanosoma cruzi infection. Lancet 348: 1407-1413, 1996.

2. Borges-Pereira J. Doença de Chagas humana: estudo da infecção crônica, morbidade e mortalidade em Virgem da Lapa, MG, Brasil (1976-1996). Tese de doutorado, Instituto Oswaldo Cruz, Rio de Janeiro, 1997.

3. Borges-Pereira J, Willcox HPF, Coura JR. Morbidade da doença de Chagas. III - Estudo longitudinal de seis anos em Virgem da Lapa, Brasil. Memórias do Instituto Oswaldo Cruz 80: 63-71, 1985.

4. Borges-Pereira J, Willcox HPF, Coura JR. Níveis de anticorpos (IgG) contra $T$. cruzi e freqüências de cardiopatia crônica chagásica em pacientes de duas áreas endêmicas do Brasil. In: Anais da II Reunião de Pesquisa Aplicada em Doença de Chagas p. 17, 1985

5. Castro AM, Rocha IR, Ferreira LM, Luquetti AO. Diagnóstico sorológico da doença de Chagas. Diminuição da reatividade no teste imunoenzimático (ELISA) em soros conservados em geladeira. Revista da Sociedade Brasileira de Medicina Tropical 27 (supl I): 180, 1994.
6. Castro CN. Estudo longitudinal da parasitemia na doença de Chagas crônica e sua correlação com a evolução clínica. Tese de Doutorado, Faculdade de Medicina da Universidade Federal de Minas Gerais, Belo Horizonte, MG, 1983.

7. Coura JR, Abreu LL, Borges-Pereira J, Willcox HPF. Morbidade da doença de Chagas. IV - Estudo longitudinal de dez anos em Pains e Iguatama, Minas Gerais, Brasil. Memórias do Instituto Oswaldo Cruz 80: 73-80, 1985.

8. Dias JCP. The indeterminate form of human chronic Chagas disease. A clinical epidemiological review. Revista da Sociedade Brasileira de Medicina Tropical 22: 147-156, 1989.

9. Estani SS, Segura EL, Ruiz AM, Velazquez E, Porcel, BM, Yampotis C. Efficacy of chemotherapy with benznidazol in children in the indeterminate phase of Chagas' disease. American Journal of Tropical Medicine and Hygiene 59: 526529, 1998.

10. Gusmão R, Rezende JM, Rassi A, Gam AA, Neva FA. Antibody levels to Trypanosoma cruzi in infected patients with and without evidence of chronic Chagas' disease. American Journal of Tropical Medicine and Hygiene 31: 452-458, 1982.

11. Israelski DM, Sadler R, Araujo F. Antibody response and antigen recognition in humann infection with Trypanosoma cruzi. American Journal of Tropical Medicine and Hygiene 39: 445-455, 1988. 
12. Khoury EL, Diez C, Cossio PM, Arana RM. Heterophil nature EVI antibody in Trypanosoma cruzi infection. Clinical Immunology and Immunopatholgy 27: 283-288, 1983.

13. Laranja FS, Dias E, Nóbrega GC, Miranda A. Chagas' disease. A clinical, epidemiological and pathologic study. Circulation 14: 1035-1060, 1956.

14. Llinares FJB. 1991. Estudo da resposta imune humoral na infecção chagásica crônica.Tese de Mestrado, Instituto de Microbiologia da UFRJ, Rio de Janeiro, RJ, 1991.

15. Luquetti AO, Rassi A, Tavares SBN, Oliveira RA, Rassi GG. Ausência de oscilação temporal no título de anticorpos de pacientes com infecção chagásica crônica. Revista da Sociedade Brasileira de Medicina Tropical 32 (supl I): 78, 1999.

16. Magnani MAC, Ferriolli Filho F, Siqueira AF. Imuneglobulinas específicas (IgA, IgG, e IgM) em soros de chagásicos crônicos verificadas por reações de imunofluorescência indireta. Revista do Instituto de Medicina Tropical de São Paulo 15: 72-75, 1973.

17. Oelemann WMR, Teixeira MGM, Costa GCV, Peralta JM, BorgesPereira J, Castro JAF \& Coura JR. Chagas' disease serology. Reactivity classification of serum panels obtained in four different areas in Brazil. Memórias do Instituto Oswaldo Cruz 91(supl): 262, 1996.

18. Peralta JM, Manigot DA, Musceli EO, Magalhães TC, Almeida EA Bastos A. Vascular endothelial and peripheral nerve antibodies in chronic Chagas' infection. Study of patients with different clinical forms. Revista do Instituto de Medicina Tropical de São Paulo 24: 6-10, 1982.

19. Primavera KSC, Umezawa ES, Peres BA, Camargo ME, Hoshino-Shimizu S. Chagas' disease: $\mathrm{Ig} / \mathrm{A}, \mathrm{Ig} / \mathrm{M}$ and $\mathrm{Ig} / \mathrm{G}$ antibodies to $T$. cruzi amastigote, trypomastigote and epimastigote antigens inacute and in different chronic forms of the disease. Revista do Instituto de Medicina Tropical de São Paulo 32: 172-180, 1990.

20. Santos-Buch CA, Teixeira ARL. The immunology of experimental Chagas' disease. III - Rejection of allogenic heart cells in vitro. Journal of Experimental Medicine 140: 38-53, 1974.

21. Szarfman A, Luquetti A, Rassi A, Rezende JM, Schimunis GA. Tissue-reacting immunoglobulins in patients with different clinical forms of Chagas' disease. American Journal of Tropical Medicine and Hygiene 30: 43-46, 1981.

22. Teixeira ARL, Pereira LM. Discrepâncias entre resultados de três reações sorológicas empregadas para diagnóstico da doença de Chagas. Revista Brasileira de Biologia 41: 789795, 1981.

23. Teixeira MGM, Borges-Pereira J, Peralta JM. Avaliação de testes sorológicos aplicados para a detecção de infecção pelo Trypanosoma cruzi. Revista Brasileira de Patologia Clínica 30: 133-139, 1994.

24. Titto EH, Moreno M, Braun M, Segura EL. Chagas' disease: humoral response to subcellular fraction of Trypanosoma cruzi in symptomatic and asymptomatic patients. Tropical Medicine and Parasitology 38: 163-166, 1987.

25. Willcox HPF, Borges-Pereira J, Coura JR. A sorologia no trabalho de campo - Transporte e conservação. Revista da Sociedade Brasileira de Medicina Tropical 22(supl II): 103, 1989.

26. Zauza PL. Avaliação dos níveis de anticorpos (IgG) anti- $T$. cruzi em soros de pacientes chagásicos crônicos de Virgem da Lapa, Minas Gerais, Brasil. Tese de Mestrado, Instituto Oswaldo Cruz, FIOCRUZ, Rio de Janeiro, RJ, 2000. 